\title{
E-WS: A Novel Smart Information System Towards Smokers for the Outdoor Canteen Environment
}

\author{
Muhammad Ali BUCHARI ${ }^{1}$, Kemahyanto EXAUDI ${ }^{2 *}$, Clara Agustina
}

\author{
HERAWATI $^{3}$, Huda UBAYA ${ }^{4}$, Sarmayanta SEMBIRING ${ }^{5}$, Osvari ARSALAN ${ }^{6}$, and \\ Purwita SARI ${ }^{7}$
}

${ }^{1,6}$ Departement of Informatics Engineering, Faculty of Computer University of Sriwijaya, Indonesia

2,3,4,5 Departement of Computer Engineering, Faculty of Computer University of Sriwijaya, Indonesia ${ }^{7}$ Departement of Information System, Faculty of Computer University of Sriwijaya, Indonesia "Corresponding author: kemahyanto@ilkom.unsri.ac.id

\begin{abstract}
The most critical component of the environment for living things is air. Poor air quality influenced by carbon monoxide (CO) gas. Cigarette smoke is one of the best contributors to carbon monoxide today. The habit of smokers does not heed the sign of no smoking in many places, for example, the Canteen (cafeteria). This research presents a new intelligent information system to prevent smokers in the outdoor cafeteria environment. We provide this case solution as an Early Warning System (E-WS), by utilizing the MQ gas sensor and buzzer. In this case, the MQ gas sensor is used to detect CO gas coming from cigarette smoke. The proposed system is implemented directly for $\mathrm{CO}$ gas from cigarette smoke, grill smoke, burnt smoke, and vehicle fumes for E-WS validation. The value of air quality (PPM) is determined based on parameters Good (0-50), Medium (51-100), and Danger (> 101). The PPM value displayed in the Dot Matrix DMD P10 Display as air quality information and active buzzer marker. The test data shows that the E-WS successfully detected CO gas with different PPM values. And the buzzer is active when the ppm value is in the moderate to dangerous category.
\end{abstract}

Keywords: air pollution, carbon monoxide (CO), E-WS, MQ sensor

\section{Introduction}

The most critical environmental component for living things is air. To be able to enjoy the fresh air, it is necessary to consider the quality of the air itself. Poor air quality can be influenced by several factors, which are also called air pollution [1]. One of the factors causing the decrease in the level of clean air quality caused by carbon monoxide (CO) gas. $\mathrm{CO}$ gas that is often found aside from vehicle fumes is cigarette smoke. $\mathrm{CO}$ gas is a type of odorless gas where the element produced from incomplete combustion of carbon or carbon [2]. But it has gas molecules poisonous to the human body $[5,2,9]$. Each $\mathrm{CO}$ gas molecule consists of one carbon atom, which covalently bonded to one oxygen atom [10]. The unit for $\mathrm{CO}$ concentration in air is parts per million (ppm) [11]. Based on the Air Pollution Standard Index (ISPU) Number KEP107 / KABAPEDAL / 11/1997, article 9 explains that the numbers and categories of air pollution standard indexes for carbon monoxide gas shown in Table 1.

Table 1 CO levels in the Air Pollution Standard Index Categories for Carbon Monoxide Gas [12]

\begin{tabular}{|c|c|c|}
\hline Category & CO $(\mathbf{p p m})$ & Indicator \\
\hline Good & $0-50 \mathrm{ppm}$ & Green Color \\
\hline Medium & $51-100 \mathrm{ppm}$ & Blue \\
\hline Unhealthy & $101-199 \mathrm{ppm}$ & Yellow \\
\hline Very Unhealthy & $200-299 \mathrm{ppm}$ & Red Color \\
\hline Harmful & $>300 \mathrm{ppm}$ & Black Color \\
\hline
\end{tabular}


The cigarette is the wrong one major cause of deadly cardiovascular disease [3]. Therefore air pollution that requires special attention is pollution originating from motor vehicle fumes, cigarette smoke, and other particles. Smoker's behavior explained as an act of smoking a tobacco roll that is burned and exhaling the smoke out of the body [13]. Exhaled smoke can be sucked back by smokers and those around them. This can harm health. Cigarette smoke has carbon dioxide gas compounds, water, carbon monoxide, and other toxic compounds. The very high concentration of compounds in cigarette content is carbon monoxide [14]. CO gas concentration can cause death if inhaled continuously for 30 minutes [3].

According to the research conducted by Inayatillah et al., 2014 showed that the average $\mathrm{CO}$ level in smokers was 22 ppm while non-smokers amounted to $5.83 \mathrm{ppm}$ [4]. Based on the unit value of this CO concentration (ppm), Lin et al. 2018 explain that $\mathrm{CO}$ levels can be monitored using sensors [5]. Air pollution needs to be detected so that the levels of dirty air so as not to become a health risk for humans and other living things. MQ family sensor is a sensor that is usually used to determine the content of ppm levels in the air, to see the quality and condition of the Air. Air pollution is an easy thing for everyone to forget about this issue of air pollution, air pollution is a real problem that threatens the environment and even threatens us, every time and every day [6] [4].

Previous studies have examined the effect of cigarette smoke on the body of smokers in the environment of the Faculty of Computer Science (Fasilkom). From the tests conducted, it can be concluded that active and passive smokers have a considerable influence on air pollution caused in the surrounding environment. Therefore this research has succeeded in developing the MQ gas sensor to detect cigarette smoke in the Fasilkom cafeteria environment to anticipate the occurrence of air pollution from cigarette smoke. This study also uses an alarm as a sign that air has polluted by cigarette smoke and provides information on the level of air pollution around the environment of the Facilitator.

\section{1) Proposed Early Warning System}

Overall the proposed E-WS system in this study can be seen in Figure 1. The process of taking and processing the test data is carried out to provide air quality information to the monitoring user.

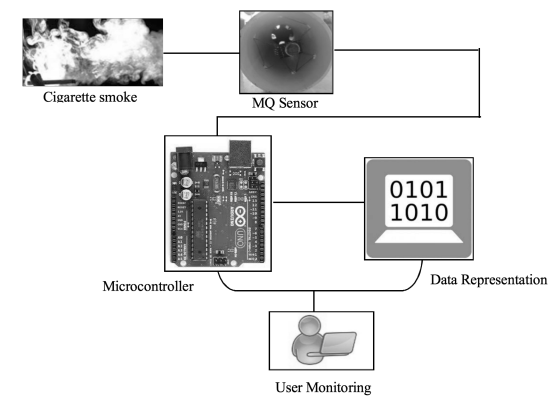

Figure 1. E-WS System Architecture

Based on Figure 1 explains that the sensor detects $\mathrm{CO}$ gas in the surrounding environment. Every time there is a CO gas from cigarette smoke that is exposed, the sensor sends information to the Acquisition Data system to get the sensor data. The process is done to simplify and speed up the work of the microcontroller in processing data received. The output from the microcontroller then represented as data that can be understood by the user. So, in this case, the user can find out air quality information expressed in PPM values.

\section{2) System Hardware}

The hardware system in this study consists of three main parts, namely Input represented by an MQ gas sensor, Processor represented by an Arduino microcontroller and output represented by an indicator light, Alarm, and DMD Display. For more details can be seen in Figure 2.

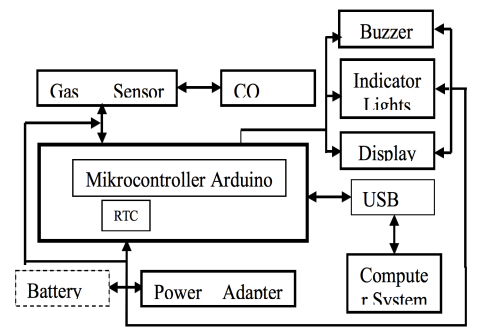

Figure 2. Gas Sensor Hardware System in E-WS

Gas sensor hardware system is simulated using proteus using one MQ-2 sensor as input, Arduino Uno as a processor, LED as an indicator of air quality, LCD 16x2 as a PPM information viewer, and alarm as a danger marker. The simulation is done first to test the system designed to minimize the possibility of errors that occur before it implemented. For more details, can be seen in Figure 3 below.

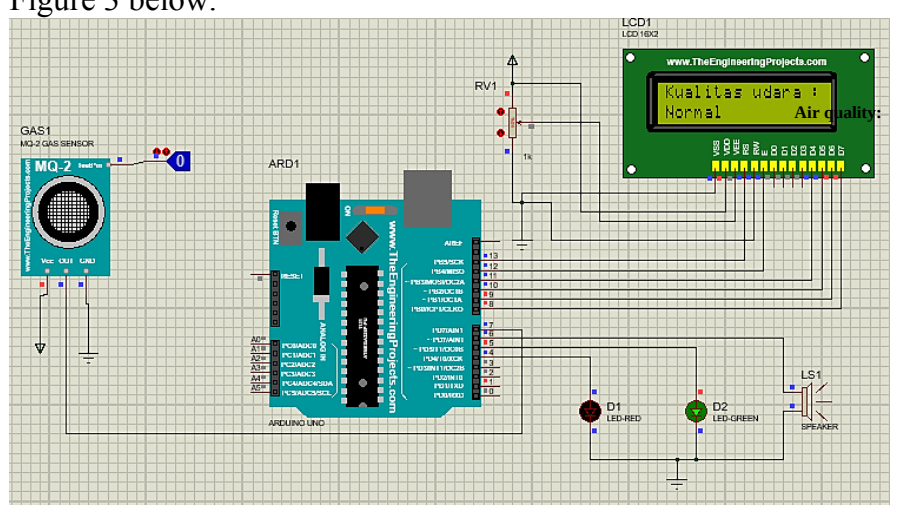

Figure 3. Simulation of the MQ sensor circuit in Proteus

\section{3) Result}

In this section, we will focus on the success rate of the EWS system in detecting cigarette smoke pollution in the surrounding environment. Air pollution has taken from the location of the outdoor cafeteria on the Fasilkom Unsri campus. The data presented generated from five different days with different sample times. 


\section{PERFORMANCEEVALUATION OFTHE E-WSSYSTEM IN THE OUTER ENVIRONMENT}

Based on the design shown in Figure 2 explains that the installation of this monitoring system is very precisely installed in the position, as shown in Figure 4. This monitoring proves that visitors very quickly see the air display in the cafeteria because it is in the center position from the cafeteria. The installation of the sensor on one of the dining tables in the cafeteria is because more visitors sit at this table for reasons of a comfortable position, there are electrical plugs and have wide air circulation from the left and right. The survey results of determining the location of the device carried out for five days during the campus activity hours, starting from 8:30 until 17:00.

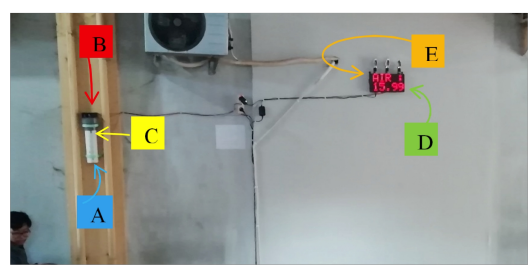

Figure 4. Results of the implementation of the E-WS system; incoming airflow through the sensor MQ (A), the fan as a vacuum to speed up the detection process (B), the pipe box as a place for air circulation to the sensor (C), the value of the surrounding air quality in PPM units (D), air display information $(\mathrm{E})$.

Table 2 Data Visitor Diner on hours and days of active lectures

\begin{tabular}{|c|c|c|c|}
\hline Day & Time & $\begin{array}{c}\text { Number of } \\
\text { Visitors (People) }\end{array}$ & $\begin{array}{l}\text { Total seating position in a } \\
\text { location sensor (people) }\end{array}$ \\
\hline \multirow[t]{3}{*}{ Monday } & Morning & 10 & 3 \\
\hline & Afternoon & 15 & 8 \\
\hline & Evening & 7 & 3 \\
\hline \multirow[t]{3}{*}{ Tuesday } & Morning & 2 & 2 \\
\hline & Afternoon & 23 & 10 \\
\hline & Evening & 11 & 7 \\
\hline \multirow[t]{3}{*}{ Wednesday } & Morning & 5 & 3 \\
\hline & Afternoon & 17 & 12 \\
\hline & evening & 16 & 11 \\
\hline \multirow[t]{3}{*}{ Thursday } & Morning & 3 & 3 \\
\hline & afternoon & 8 & 5 \\
\hline & evening & 5 & 5 \\
\hline \multirow[t]{3}{*}{ Friday } & Morning & 6 & 1 \\
\hline & afternoon & 7 & 7 \\
\hline & evening & 12 & 10 \\
\hline
\end{tabular}

Based on Table 2 explains that when the survey divided into three parts, Morning (8:30 to 12:00), afternoon (12:00 to $15: 00)$, and in the evening (15:00 to 17:00). This survey is done to determine the population of visitors more in the morning, afternoon, or evening. The average cafeteria visitor based on samples taken for five days shows that 
Testing is carried out in a few days in the cafeteria environment. The results data displayed in this study taken for three days on 10 - 12 September 2019. The testing time was carried out from 8.35 to 17.00. The division of time categorized into three parts, namely Morning, Afternoon, and Evening, as described in Table 2. One of the results of tests that have been carried out for three days of testing is on 10 September 2019. Divided into two parts, as shown in Table 3 and Table 4.

Table 3. Test results on September 10, 2019 (Morning to Afternoon), the condition consisted of smoke and no cigarette smoke

\begin{tabular}{|l|c|c|c|c|}
\hline $\begin{array}{l}\text { Nu } \\
\mathbf{m b} \\
\text { er }\end{array}$ & $\begin{array}{c}\text { Environmental } \\
\text { Conditions } \\
\text { Cafetaria }\end{array}$ & $\begin{array}{c}\text { Air Quality } \\
\text { (PPM) }\end{array}$ & $\begin{array}{c}\text { Indicator } \\
\text { Light }\end{array}$ & Remarks \\
\hline $\mathbf{1 .}$ & No smoke & 40 & Green Light & Normal \\
\hline $\mathbf{2 .}$ & No smoke & 51 & Yellow Light & Medium \\
\hline $\mathbf{3 .}$ & No smoke & 49 & Green Light & Normal \\
\hline $\mathbf{4 .}$ & No smoke & 75 & Red Light & Danger \\
\hline $\mathbf{5 .}$ & Cigarette Smoke & 120 & Red Light & Danger \\
\hline
\end{tabular}

Table 4. Test results on September 10, 2019 (Afternoon to Evening), the condition consisted of smoke and no cigarette smoke

\begin{tabular}{|l|c|c|c|c|}
\hline $\begin{array}{l}\text { Nu } \\
\mathbf{m b} \\
\text { er }\end{array}$ & $\begin{array}{c}\text { Environmental } \\
\text { Conditions } \\
\text { Cafetaria }\end{array}$ & $\begin{array}{c}\text { Air Quality } \\
\text { (PPM) }\end{array}$ & Indicator Light & Remarks \\
\hline $\mathbf{1 .}$ & No smoke & 90 & Yellow Light & Medium \\
\hline $\mathbf{2 .}$ & No smoke & 105 & Red Light & Danger \\
\hline $\mathbf{3 .}$ & There is smoke & 50 & Green Light & Normal \\
\hline $\mathbf{4 .}$ & No smoke & 110 & Red Light & Danger \\
\hline $\mathbf{5 .}$ & $\begin{array}{c}\text { Cigarettes } \\
\text { Smoke }\end{array}$ & 110 & Red Lights & Danger \\
\hline
\end{tabular}

Air PPM data from the test results shown in Table 3 and Table 4 concludes that the air quality monitoring system in the Fasilkom cafeteria environment, especially for cigarette smoke, has been successfully implemented. The data shown in Table 3 shows that from the 5 test samples taken, the system was able to correctly detect air quality when there was smoke in the test environment. In point 4 , the system detects that the air PPM value is 75 with an indication of danger. Yet when testing conducted, there was no cigarette smoke around the test environment. Based on this data, the researchers concluded that the system created not only detects cigarette smoke. So it can be assumed that the monitoring system detects the presence of combustion products other than cigarettes: example, smoke from the burnt cafeteria or smoke from motor vehicles around the parking lot. The data test was shown in Table 4 in points 2, 3, and 4. 
[5] C. Lin, X. Xian, X.Qin, D.Wang, F.Tsow, E.Forzani, N.Tao, "High Performance Colorimetric Carbon Monoxide Sensors for Continuous Personal Exposure Monitoring," ACS Sensors, vol. 3, no. 2 , pp. 327-333, 2018.

[6] KM Ng, M. Azri, H. Mohd, A. Ahmad, NA Razak, and S. Alam, "Remote Air Quality Monitoring Systems by Using MyRIO-LabVIEW, "System 2018 9th IEEE Control. Grad. Res. Colloq., vol. 9, no. August, pp. 105-109, 2018.

[7] KC Kusti, "Prototype of MicrocontrollerBased Evacuation And Warning Gas System," pp. 1-10, 2018.

[8] ARP Kusuma, "Effects of Smoking on Dental Health and Oral Cavity," Majalah Ilmiah Sultan Agung, vol. 49, no. 124, pp. $1-8,2011$.

[9] SE Meredith, A. Robinson, P. Erb, CA. Spieler, N. Klugman, P. Dutta, J. Dallery, "A mobile-phone-based carbon monoxide breath to detect cigarette smoking," Nicotine and Tobacco Research, vol. 16, no. 6, pp. 766-773, 2014.

computer science, Sriwijaya University.

\section{REFERENCES}

[1] M. Benammar, A. Abdaoui, SHM Ahmad, F. Touati, and A. Kadri, "A Modular IoT Platform for Real-Time Indoor Air Quality Monitoring," Sensors, pp. 1-18, 2018.

[2] AO Goldstein, SP Gans, C. RipleyMoffitt, C. Kotsen, and M. Bars, "Use of Expired Air Carbon Monoxide Testing in Clinical Tobacco Treatment Settings," Chest, vol. 153, no. 2, pp. 339-348, 2018.

[3] L. Berkowitz, Bárbara M. Schultz, Geraldyne A. Salazar, Catalina. Pardo-

Roa, Valentina P. Sebastián, Manuel M.

Álvarez-Lobos, Susan M. Bueno, "Impact of Cigarette Smoking on the Gastrointestinal Tract Inflammation: Opposing Effects in Crohn's Disease and Ulcerative Colitis," Frontiers in Immunology. Vol. 9, p. 74, 2018.

[4] IR Inayatillah, E. Syahrudin, and AD Susanto, "Examination of Carbon Monoxide Levels in Air Smokers and Non-Smokers and Factors Affecting," $J$. Respirology Indonesia., vol. 34, no. 4, pp. 180-90, 2014.
[10] Susanty Dewi Winata, "Early Detection of Carbon Monoxide Intoxication," $J$. Kedokteran. Meditek No. 42A, vol. 16, pp. 26-28, 2010.

[11]E. Nebath, D. Pang, and JO Wuwung, "Design and Design of Hazardous Gas Measuring Devices for $\mathrm{CO}$ and $\mathrm{CO} 2$ in Industrial Environments," E-Journal Tech. Electro and Computer, pp. 65-72, 2014.

[12] Bapedal, "Technical Guidelines for Calculation and Reporting and Information on Air Polluter Standard Index," Ministry of Environment and Forestry, 1997.

[13] Saminan, "Effects of smoking behavior on the respiratory tract," Kedokteran Syiah Kuala, vol. 16, no. 3, pp. 1-3, 2016.

[14] SA Glantz and DW Bareham, "ECigarettes: Use, Effects on Smoking, Risks, and Policy Implications," Annual Review of Public Health, vol. 39, no. 1, pp. 215-235, 2018. 